\title{
Impact on quality of life after vagus nerve and phrenic nerve guided systematic nodal dissection for non-small cell lung cancer patients: a prospective, single-arm clinical trial
}

\author{
Yao Liu ${ }^{1 \#}$, Weixiong Yang ${ }^{1 \#}$, Jiali Yang ${ }^{1}$, Shufen Liao ${ }^{2}$, Zhenguo Liu ${ }^{1}$, Bo Zeng ${ }^{1}$, Chao Cheng ${ }^{1}$ \\ ${ }^{1}$ Department of Thoracic Surgery, The First Affiliated Hospital of Sun Yat-sen University, Guangzhou, China; ${ }^{2}$ Operating Room of The First \\ Affiliated Hospital of Sun Yat-sen University, Guangzhou, China \\ Contributions: (I) Conception and design: Y Liu, W Yang, C Cheng; (II) Administrative support: None; (III) Provision of study materials or patients: \\ Z Liu, B Zeng; (IV) Collection and assembly of data: Y Liu, J Yang, S Liao; (V) Data analysis and interpretation: Y Liu, W Yang; (VI) Manuscript \\ writing: All authors; (VII) Final approval of manuscript: All authors. \\ \#These authors contributed equally to this work. \\ Correspondence to: Chao Cheng. Department of Thoracic Surgery, The First Affiliated Hospital of Sun Yat-sen University, 58 Zhongshan 2nd Road, \\ Guangzhou 510080, China. Email: chengch3@mail.sysu.edu.cn.
}

\begin{abstract}
Background: Patients with non-small cell lung cancer (NSCLC) suffer a decrease in quality of life (QOL) after receiving curative lobectomy and mediastinal lymph node dissection via video-assisted thoracoscopic surgery (VATS). We aimed to explore the preliminary influence of our modified approach called the duonerve-guided systematic nodal dissection (SND) on patients' QOL.

Methods: Between October 2018 and March 2019, 21 patients were enrolled from the First Affiliated Hospital of Sun Yat-sen University and received curative lobectomy and duo-nerve-guided SND for clinical stage I to IIIA NSCLC. Participants' QOL was evaluated by Functional Assessment of Cancer TherapyLung (FACT-L) questionnaire before operation and at 1- and 3-month postoperatively.

Results: The overall QOL scores at 1 month after surgery were significantly lower than those before surgery (116.13 vs. 126.63, $\mathrm{P}=0.001$ ), while there was no significant difference in the overall QOL score between preoperative and 3 months after surgery. In particular, among the 5 subscales, physical well-being (PWB), functional well-being (FWB), and trial outcome index (TOI) significantly declined at 1 month after surgery. However, each subscale showed significant improvement at 3 months after operation compared with that at 1 month and basically returned to the level at baseline. In addition, there was a significant improvement in the emotional well-being (EWB) domain 3 months after surgery (23.00 vs. 18.00, $\mathrm{P}=0.001)$.

Conclusions: As evidenced by patients' QOL at 3 months after receiving duo-nerve-guided SND being not significantly different from that at baseline, the improved SND procedure has positive effects on the fast recovery of NSCLC patients.
\end{abstract}

Keywords: Non-small cell lung cancer (NSCLC); quality of life (QOL); vagus nerve; phrenic nerve; lymph node dissection

Submitted Aug 31, 2021. Accepted for publication Dec 01, 2021.

doi: $10.21037 / \mathrm{atm}-21-5820$

View this article at: https://dx.doi.org/10.21037/atm-21-5820

\section{Introduction}

Lung cancer is the leading cause of death among cancer patients in China (1). According to the European Society of Thoracic Surgeons (ESTS) guideline for lung cancer resection, systematic nodal dissection (SND) is recommended for most operable non-small cell lung cancer (NSCLC) patients so as to ensure complete resection (2). Video-assisted thoracoscopic surgery (VATS) has 
been widely used in radical resection of NSCLC for its shorter hospital stay (3) and lower incidence of related pain (4) compared with thoracotomy. However, the short (1-3 months)- and long-term (12 months) quality of life (QOL) of patients receiving VATS have been significantly affected, especially in terms of physical condition (5). Nerve injury is one of the major causes that lead to the deterioration of QOL $(6,7)$. Persistency of nerve injuryrelated symptoms such as persistent cough greatly affect patients' QOL. Previous several reports have speculated that C-fibers arising from vagal afferent nerve play an important role in regulating cough reflex $(7,8)$.

Though previous studies have emphasized the importance of nerve preservation during lung cancer surgery and provided useful techniques, most of these studies have been case reports or retrospective analyses $(6,9,10)$. Some articles have put forward the ideas of surgical modification and nerve protection (11); however, prospective evaluation of the clinical efficacy of the modified procedure has been rarely conducted.

We previously established a modified procedure called the duo-nerve-guided SND that emphasizes preserving the vagus and phrenic nerves during lymph node dissection. We divided mediastinal lymph nodes into 3 areas according to the anatomical site of the two nerves, and dissected the lymph nodes in these 3 areas separately (12). This modified procedure may reduce symptoms such as persistent cough and dyspnea and enhance recovery of QOL. However, further exploration and analysis of the influence of our modified approach on patients' QOL have not been carried out. By comparing changes in QOL scores between preoperative and postoperative 1 and 3 months, we aimed to explore the preliminary influence of our modified approach on patients' QOL. We present the following article in accordance with the TREND reporting checklist (available at https://dx.doi. org/10.21037/atm-21-5820).

\section{Methods}

\section{Study design and participants}

We conducted this prospective, single-arm pilot study at the First Affiliated Hospital of Sun Yat-sen University. All procedures performed in this study involving human participants were in accordance with the Declaration of Helsinki (as revised in 2013). The study was approved by the Ethics Committee and Institutional Review Board of
Guangdong Association Study of Thoracic Oncology (No. A2018-006) and informed consent was taken from all the patients. The study protocol was registered in the Chinese Clinical Trial Registry (Identifier: ChiCTR1800018461)

The patient eligibility criteria were as follows: (I) aged 18-75 years; (II) without preoperative neoadjuvant chemoradiotherapy; (III) scheduled for thoracoscopic radical resection of lung cancer with SND; (IV) an Eastern Cooperative Oncology Group (ECOG) performance status score of 0 or 1 . The exclusion criteria were as follows: (I) a history of other malignant tumor in 5 years prior to this study; (II) HIV seropositive; (III) pregnant or lactating; (IV) tumor mixed with small-cell lung cancer; (V) a history of neurological or psychiatric disorders, including epilepsy or dementia. The withdrawal criteria included: (I) histopathological confirmation of non-R0 resection of NSCLC intraoperatively or postoperatively; (II) final diagnosis was not NSCLC; (III) failure to complete the questionnaire as requested in the protocol.

\section{Preoperative data collection}

Preoperative evaluation was conducted including computed tomography (CT) scans of the chest. Additional CT scans of the abdomen along with magnetic resonance imaging (MRI) of the head would be used to exclude distant metastasis or could be replaced by positron emission tomography-computed tomography (PET-CT) scan. Endobronchial ultrasonography (EBUS) was conducted if necessary, but was not routinely used. All participants were staged according to the 8th edition of the American Joint Committee on Cancer (AJCC) lung cancer staging classification (13). Patients were enrolled in the study 1 or 2 days before their surgery and completed the questionnaire for assessment of QOL.

\section{Outcome measures}

The Functional Assessment of Cancer Therapy-Lung (FACT-L) questionnaire was used to evaluate QOL (Appendix 1). The simplified Chinese version of FACT-L is of good reliability, validity, and responsiveness for patients with lung cancer in China (14). The FACT-L consists of 36 items with 5 subscales to measure the QOL of patients with lung cancer in the past 7 days. Each subscale uses a Likert scale of 0 to 4 , with 0 indicating "not at all" and 4 "very much". The 5 subscales are: emotional well-being (EWB; 6 items), functional well-being (FWB; 7 items), 


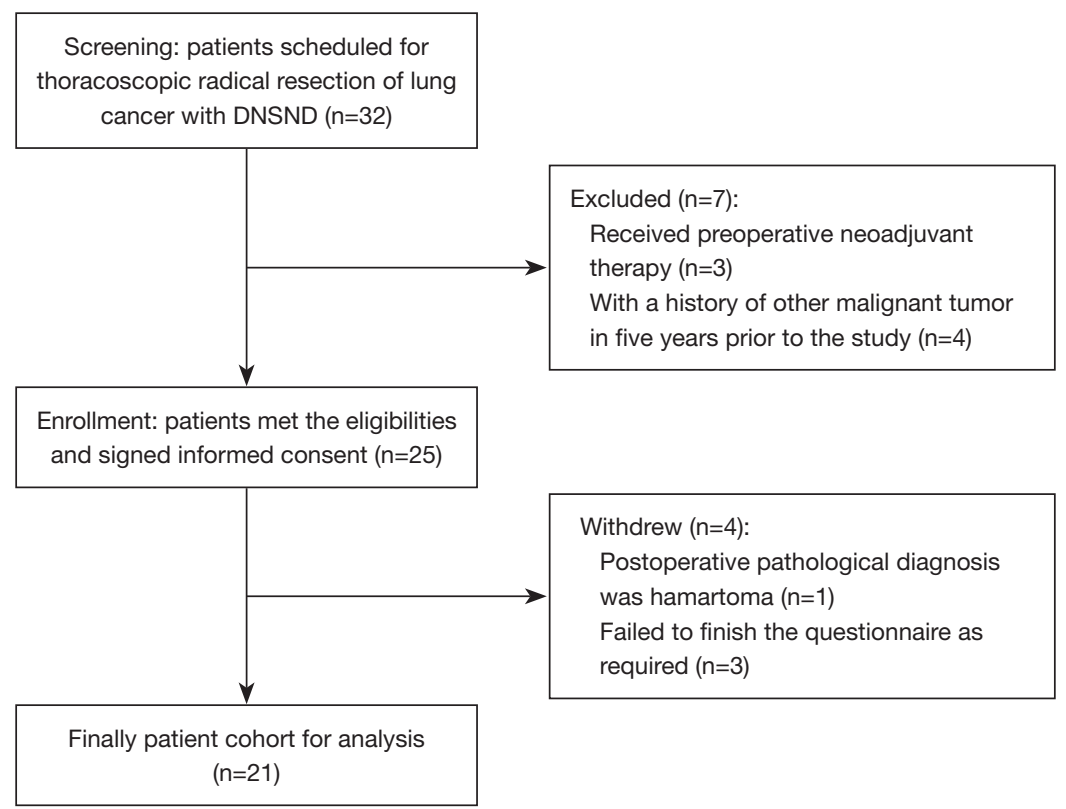

Figure 1 Flowchart of the study. DNSND, duo-nerve-guided systematic nodal dissection.

physical well-being (PWB; 7 items), and social well-being (SWB; 7 items), and lung cancer subscale (9 items). Trial outcome index (TOI) was the sum of FWB, PWB, and lung cancer subscale. The score of the QOL was the sum of all items, with higher scores representing better QOL. Some of the items need to be reversely coded for the calculation. These reverse coding questions are similar to setting some trap questions which can prevent patients making obvious logic errors in finishing the questionnaires.

To ensure that the range of scores of each domain would be equivalent to scores for the complete measurement, the 4 subscales scores (PWB, SWB, EWB, FWB) were prorated. For example, the PWB subscale has 7 items and if only 6 were answered, the prorated score for the PWB would be computed by multiplying the sum of individual PWB items by 7 and then dividing the sum by 6 (15).

\section{Surgery and postoperative follow-up}

All patients included in our study received duo-nerveguided SND during the surgery (12). Participants returned to the hospital for their regular visits at 1- and 3-month after the surgery during which they were asked to complete a follow-up paper-based FACT-L questionnaire. Data on demographic characteristics, lifestyle, operative information, and clinical outcomes of the eligible participants were collected.

\section{Statistical analysis}

Characteristics of participants were presented as means and standard deviations for continuous variables and frequencies and percentages for categorical variables. The scores of QOL were non-normally distributed, and we use the median to represent scores of QOL. Wilcoxon matchedpairs signed-rank tests were performed to compare the differences between preoperative baseline QOL scores and those at 1- and 3-month time points for the overall and subscales of QOL. Statistical significance was considered when $\mathrm{P}$ value $<0.05$. The analyses were performed using SPSS version 22 (IBM-SPSS, Inc., Armonk, NY, USA).

\section{Results}

\section{Overview of the trial and Patients' characteristics}

Between 8 October 2018 and 31 March 2019, 32 patients were screened for eligibility, and 25 eligible patients were enrolled after signing informed consents. There were 4 patients who withdrew from the study, among whom, 3 failed to finish the questionnaire as required and 1 was diagnosed with hamartoma according to the postoperative pathological examination. Eventually, 21 patients were included in the final analysis (Figure 1).

Among the 21 participants, the mean age was $56.43 \pm 10.05$ years and $52.4 \%(11 / 21)$ of them were male. 
Table 1 Clinical characteristics of the 21 patients who underwent curative lobectomy and duo-nerve-guided SND for NSCLC $(n=21)$

\begin{tabular}{|c|c|}
\hline Variable & Number of patients (\%) \\
\hline Age & $56.43 \pm 10.05$ \\
\hline \multicolumn{2}{|l|}{ Gender } \\
\hline Male & $11(52.4)$ \\
\hline Female & $10(47.6)$ \\
\hline \multicolumn{2}{|l|}{ Smoking } \\
\hline Yes & $9(42.8)$ \\
\hline No & $12(57.2)$ \\
\hline \multicolumn{2}{|l|}{ BMI } \\
\hline$<18$ & $1(4.8)$ \\
\hline $18-23$ & $8(38.1)$ \\
\hline$>23$ & $12(57.1)$ \\
\hline \multicolumn{2}{|l|}{ Tumor location } \\
\hline RUL & $8(38.1)$ \\
\hline RML & $2(9.5)$ \\
\hline RLL & $1(4.8)$ \\
\hline LUL & $2(9.5)$ \\
\hline LLL & $8(38.1)$ \\
\hline \multicolumn{2}{|l|}{ Histology } \\
\hline Squamous cell carcinoma & $2(9.5)$ \\
\hline Adenocarcinoma & $17(81.0)$ \\
\hline Other type & $2(9.5)$ \\
\hline \multicolumn{2}{|l|}{ Preoperative TNM stage } \\
\hline \multicolumn{2}{|l|}{ T stage } \\
\hline $\mathrm{T} 1$ & $13(61.9)$ \\
\hline $\mathrm{T} 2$ & 7 (33.3) \\
\hline T3 & $1(4.8)$ \\
\hline \multicolumn{2}{|l|}{ N stage } \\
\hline NO & $16(76.2)$ \\
\hline $\mathrm{N} 1$ & $1(4.8)$ \\
\hline N2 & $4(19.0)$ \\
\hline \multicolumn{2}{|l|}{ Clinical stage } \\
\hline I & $15(71.4)$ \\
\hline II & $2(9.5)$ \\
\hline III & $4(19.1)$ \\
\hline
\end{tabular}

Data presented as the number of patients or mean \pm standard deviation. Figures in parentheses indicate percentage. SND, systematic nodal dissection; NSCLC, non-small cell lung cancer; BMI, body mass index; TNM, tumor, node metastasis; RUL, right upper lobe; RML, right middle lobe; RLL, right lower lobe; LUL, left upper lobe; LLL, left lower lobe.
Table 2 Postoperative clinical data of the 21 patients who received the new procedure

\begin{tabular}{lc}
\hline Variable & Value \\
\hline Operation duration (min) & $159.57 \pm 44.2$ \\
Blood loss (mL) & $55.42 \pm 25.41$ \\
Chest tube retention time (day) & $3.67 \pm 1.32$ \\
Postoperative hospital stay (day) & $3.81 \pm 0.93$ \\
Number of upstaging & $7(33.3)$ \\
Number of dissected lymph nodes & $28.86 \pm 11.36$ \\
\hline $\begin{array}{l}\text { Data presented as the number of patients or mean } \pm \text { standard } \\
\text { deviation. Figures in parentheses indicate percentage. }\end{array}$
\end{tabular}

A total of 9 participants $(42.8 \%)$ were current smokers. Participants were diagnosed as T1 (61.9\%), T2 (33.3\%), and T3 (4.8\%) preoperatively. A total of 16 participants were diagnosed as N0 preoperatively, while others were diagnosed as N1 (1/21), and N2 (4/21) respectively (Table 1). The mean operation duration, blood loss during surgery, chest tube retention time, and postoperative hospital stay were $159.57 \pm 44.2 \mathrm{~min}, 55.42 \pm 25.41 \mathrm{~mL}, 3.67 \pm 1.32 \mathrm{~d}$, and $3.81 \pm 0.93 \mathrm{~d}$, respectively (Table 2 ).

\section{$Q O L$}

Results of pre- and post-comparisons of QOL and its domains [physical status, social and family conditions, emotion status, functional status, lung cancer subscale (LCS), TOI] between baseline and the 1-month followup and between baseline and the 3-month follow-up are presented in Figure 2. The overall score of the QOL declined significantly at 1 month after surgery (126.63 vs. $116.13, \mathrm{P}=0.001)$. There was no significant difference in the overall QOL score between 3 months after surgery and the baseline (126.63 vs. 131.17, $\mathrm{P}=0.001)$. The scores of the subscales $\mathrm{PWB}(27.00$ vs. 23.00, $\mathrm{P}=0.002)$, FWB (25.00 vs. 20.00, $\mathrm{P}=0.001)$, and TOI (80.50 vs. $72.00, \mathrm{P}=0.001)$ were significantly reduced from baseline to 1 month after surgery, whereas these scores were significantly improved at 3 months after surgery compared to 1 month after surgery. There were no significant differences between baseline and the 3-month follow-up in the scores of PWB (27.00 vs. 26.00, $\mathrm{P}=0.812$ ), FWB (25.00 vs. 23.00, $\mathrm{P}=0.396$ ), and TOI (80.50 vs. $82.50, \mathrm{P}=0.614)$. In addition, there was a significant improvement in the EWB domain at 3 months 

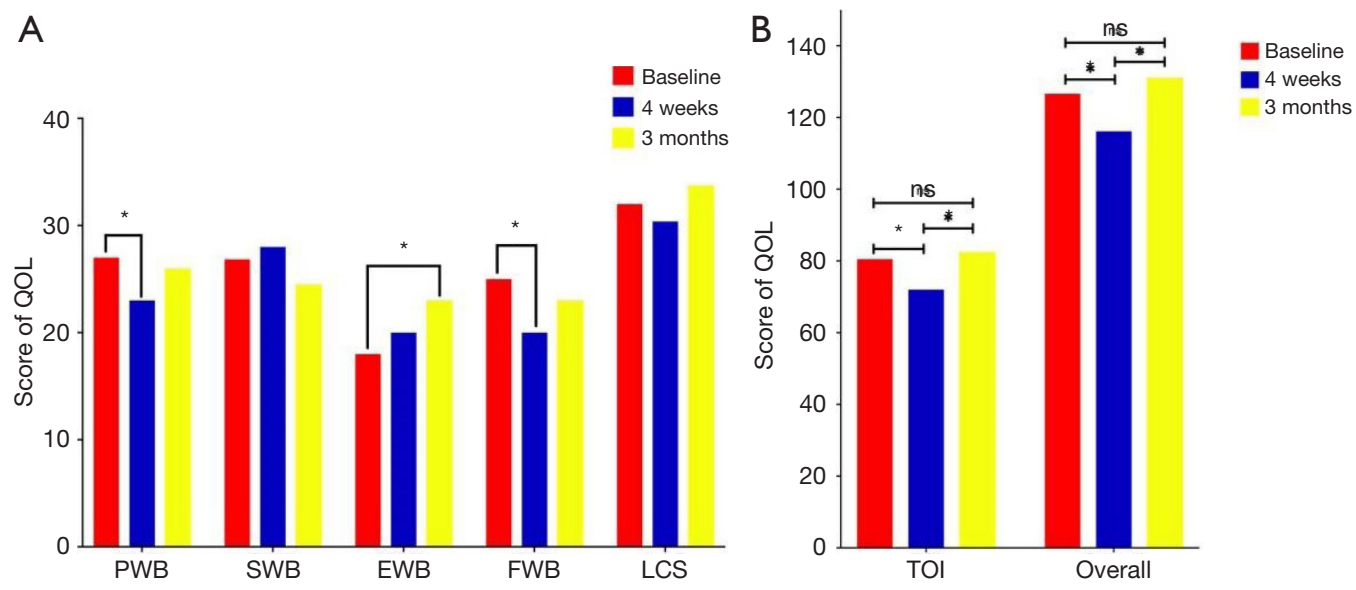

Figure 2 Comparison between preoperative and postoperative score change of FACT-L. *, P value is calculated by Wilcoxon matchedpairs signed-ranks test between preoperative score and 4 weeks postoperative score, preoperative score and 3 months postoperative score, indicates $\mathrm{P}<0.05$. QOL, quality of life; $\mathrm{PWB}$, physical well-being; SWB, social well-being; EWB, emotional well-being; FWB, functional well-being; LCS, lung cancer subscale; TOI, trial outcome index; FACT-L, Functional Assessment of Cancer Therapy-Lung.

Table 3 Changes of the detailed items in the FACT-L questionnaire

\begin{tabular}{|c|c|c|c|c|c|}
\hline Detailed items in FACT-L & $\frac{\text { Preoperative baseline }}{\text { Mean value }}$ & \multicolumn{2}{|c|}{ Postoperative 1 month } & \multicolumn{2}{|c|}{ Postoperative 3 months } \\
\hline Pain & 3.48 & 2.71 & $0.034^{*}$ & 3.43 & 0.564 \\
\hline Fatigue & 3.57 & 2.86 & $0.026^{*}$ & 3.62 & 1.000 \\
\hline Worry about getting worse & 2.43 & 2.71 & 0.437 & 3.33 & $0.005^{\star}$ \\
\hline Proud of coping with the illness & 3.14 & 3.05 & 0.809 & 3.86 & $0.008^{\star}$ \\
\hline Fear of death & 2.62 & 2.86 & 0.418 & 3.43 & $0.017^{\star}$ \\
\hline Dyspnea & 3.57 & 3.10 & $0.039^{*}$ & 3.57 & 1.000 \\
\hline Coughing & 3.14 & 2.48 & $0.046^{\star}$ & 3.48 & 0.088 \\
\hline
\end{tabular}

The mean values in the table have positive conversion, and higher scores represent better QOL; $P$ value*: The changes between baseline and postoperative 1-month QOL score were statistically significant or the changes between baseline and postoperative 3 months QOL score were statistically significant; $P$ value is calculated by Wilcoxon matched-pairs signed-ranks test. FACT-L, Functional Assessment of Cancer Therapy-Lung; QOL, quality of life.

after surgery compared to the baseline (18.00 vs. 23.00, $\mathrm{P}=0.001)$.

\section{Changes in the scores of specific items in FACT-L questionnaires}

To identify specific changes in QOL and its dimensions, we analyzed the changes of scores in each item in the questionnaire, as shown in Table 3. In the PWB domain, there were significant decreases in the scores of items related to "pain" and "fatigue" at 1 month after surgery ( 3.48 vs. $2.71, \mathrm{P}=0.034 ; 3.57$ vs. $2.86, \mathrm{P}=0.026$, respectively). However, there was no significant difference in the above items between baseline and the 3-month follow-up. As to the subscale of EWB, scores of items including "worry about getting worse", "fear of death", and "proud of coping 
with the illness" did not change significantly at 1 month after surgery, but significantly improved at 3 months after surgery compared to the baseline ( 2.43 vs. $3.33, \mathrm{P}=0.005$; 2.62 vs. $3.43, \mathrm{P}=0.017 ; 3.14$ vs. $3.86, \mathrm{P}=0.008$, respectively). In the LCS domain, scores for "shortness of breath", "cough", and "anorexia" decreased significantly at 1 month after surgery ( 3.57 vs. $3.10, \mathrm{P}=0.039 ; 3.14$ vs. $2.48, \mathrm{P}=0.046$; 3.67 vs. 3.24, $\mathrm{P}=0.047$ ), whereas there was no significant difference in scores between baseline and the 3 -month follow-up.

\section{Discussion}

This study explored the preliminary effects of the modified mediastinal lymph node dissection along the vagus nerve and phrenic nerve on the QOL of patients undergoing radical resection of NSCLC. We found that the score of overall and most dimensions of QOL of the participants had significantly deteriorated 1 month following the surgery, but returned back to the baseline at 3 months after surgery.

The overall QOL deteriorated significantly from baseline to the 1-month follow-up, especially in physical conditions. This result was consistent with previous studies about the impact of VATS lobectomy on patients' QOL (5). Factors such as pain, anorexia, dyspnea, and fatigue are considered as the major causes of the lower QOL among NSCLC post-surgery $(5,16)$. In our study, most of the dimensions of the QOL basically returned back to the level at preoperative baseline 3 months after surgery. Previous studies have reported that the QOL failed to return to the baseline level at 3 months, even at 6 months or to 1 year after surgery, especially in their physical well-being domains $(5,17)$. Findings from our study indicate that our modified procedure significantly accelerate patient recovery of postoperative QOL. Reasons for the fast recovery might be that the modified procedure tackled some important factors preventing postoperative recovery of patients' QOL such as persistent symptoms of dyspnea (58\%), fatigue (69\%), and cough (42\%) $(5,18-20)$, which were reported to be related to the injury of vagus and phrenic nerves. Phrenic nerve palsy after lobectomy can significantly reduce lung volume, which directly leads to significant reduction of respiratory parameters of forced expiratory volume in 1 second (FEV1) and forced vital capacity (FVC) (21). Dysfunction of vagus nerve can lead to postoperative shortness of breath, chest tightness, and other respiratory symptoms (22-24). Furthermore, damage of the pulmonary $\mathrm{C}$-fibers which derive from the vagus nerve can result in postoperative persistent cough (7). The duo-nerve-guided SND implemented in this trial focused on preserving these two nerves so as to alleviate the symptoms mentioned above, which may enhance fast recovery of postoperative QOL.

Results of this study showed significant improvement in patients' emotional well-being 3 months after surgery compared to that at the baseline, indicating a potentially positive impact of the modified procedure on patients' emotional improvement. By contrast, previous studies showed no statistically significant improvement in EWB in patients with conventional SND, which might be due to the combined effects of intensified pain and limited daily activities post-operatively (25). From the itemized analysis of the EWB domain, we found that patients' fear of death and worry about the deterioration of their physical conditions were significantly reduced compared with those before the operation, which might be due to the fewer postoperative complications and enhanced recovery (12). Meanwhile, the score of "coping with disease" significantly increased compared with that before surgery, suggesting that the psychological burden of participants may have been reduced and the subjective experience of coping with the disease significantly improved. The faster and enhanced recovery with fewer physical complications after surgery using the modified procedure were accompanied with significant improvement in participants' mental health, which showed a great potential of this modified procedure with positive impacts on both physical and mental wellbeings of patients.

There were still some limitations in our study. First, this was a pilot study with a limited sample size that intended to explore the initial effects of a modified and innovative procedure on patients' postoperative recovery. The measuring tools are relatively simple. Following studies will use more assessment methods to make further confirmation. Results of this study need to be interpreted with caution. Second, this was a single-arm trial without a control group. To confirm the effects and provide conclusive evidence, a multi-center fully powered randomized controlled trial (RCT) is needed to compare the effects of this modified procedure with those of the current surgical procedure.

\section{Conclusions}

In this study, we found that duo-nerve-guided SND had a significant and positive effect on postoperative QOL in patients with NSCLC at 3 months after surgery. A future RCT with a larger sample size is needed to further confirm 
the effects of this procedure in improving patients' QOL and its correlation with neuroprotection.

\section{Acknowledgments}

Funding: None.

\section{Footnote}

Reporting Checklist: The authors have completed the TREND reporting checklist. Available at https://dx.doi. org/10.21037/atm-21-5820

Data Sharing Statement: Available at https://dx.doi. org/10.21037/atm-21-5820

Conflicts of Interest: All authors have completed the ICMJE uniform disclosure form (available at https://dx.doi. org/10.21037/atm-21-5820). The authors have no conflicts of interest to declare.

Ethical Statement: The authors are accountable for all aspects of the work in ensuring that questions related to the accuracy or integrity of any part of the work are appropriately investigated and resolved. All procedures performed in this study involving human participants were in accordance with the Declaration of Helsinki (as revised in 2013). The study was approved by the Ethics Committee and Institutional Review Board of Guangdong Association Study of Thoracic Oncology (No. A2018-006) and informed consent was taken from all the patients.

Open Access Statement: This is an Open Access article distributed in accordance with the Creative Commons Attribution-NonCommercial-NoDerivs 4.0 International License (CC BY-NC-ND 4.0), which permits the noncommercial replication and distribution of the article with the strict proviso that no changes or edits are made and the original work is properly cited (including links to both the formal publication through the relevant DOI and the license). See: https://creativecommons.org/licenses/by-nc-nd/4.0/.

\section{References}

1. Chen $\mathrm{W}$, Zheng R, Baade PD, et al. Cancer statistics in China, 2015. CA Cancer J Clin 2016;66:115-32.

2. Lardinois D, De Leyn P, Van Schil P, et al. ESTS guidelines for intraoperative lymph node staging in non-small cell lung cancer. Eur J Cardiothorac Surg 2006;30:787-92.

3. Rauma V, Andersson S, Robinson EM, et al. Thoracotomy and VATS Surgery in Local Non-Small-Cell Lung Cancer: Differences in Long-Term Health-Related Quality Of Life. Clin Lung Cancer 2019;20:378-83.

4. Mei J, Guo C, Xia L, et al. Long-term survival outcomes of video-assisted thoracic surgery lobectomy for stage I-II non-small cell lung cancer are more favorable than thoracotomy: a propensity score-matched analysis from a high-volume center in China. Transl Lung Cancer Res 2019;8:155-66.

5. Avery KNL, Blazeby JM, Chalmers KA, et al. Impact on Health-Related Quality of Life of Video-Assisted Thoracoscopic Surgery for Lung Cancer. Ann Surg Oncol 2020;27:1259-71.

6. Kocher GJ, Poulson JL, Blichfeldt-Eckhardt MR, et al. The importance of phrenic nerve preservation and its effect on long-term postoperative lung function after pneumonectomy. Eur J Cardiothorac Surg 2016;49:1059-62.

7. Sawabata N, Maeda H, Takeda S, et al. Persistent cough following pulmonary resection: observational and empiric study of possible causes. Ann Thorac Surg 2005;79:289-93.

8. Canning BJ. Afferent nerves regulating the cough reflex: mechanisms and mediators of cough in disease. Otolaryngol Clin North Am 2010;43:15-25, vii.

9. Shinohara S, Yamada T, Ueda $M$, et al. Phrenic Nerve Reconstruction and Bilateral Diaphragm Plication After Lobectomy. Ann Thorac Surg 2017;104:e9-e11.

10. Chai YJ, Lee JM, Seong YW, et al. Application of Continuous Intraoperative Neuromonitoring During VATS Lobectomy for Left Lung Cancer to Prevent Recurrent Laryngeal Nerve Injury. Sci Rep 2020;10:4636.

11. Ranganathan P, Jiwnani S, Pramesh CS. Intercostal nerve protection to prevent post-thoracotomy pain. J Thorac Dis 2019;11:S1434-5.

12. Liu $\mathrm{Z}$, Liu $\mathrm{Y}, \mathrm{Xie} \mathrm{C}$, et al. Vagus nerve and phrenic nerve guided systematic nodal dissection for lung cancer. J Thorac Dis 2019;11:4021-7.

13. Detterbeck FC, Boffa DJ, Kim AW, et al. The Eighth Edition Lung Cancer Stage Classification. Chest 2017;151:193-203.

14. Wan C, Zhang C, Cai L, et al. Psychometric properties of the Chinese version of the FACT-L for measuring quality of life in patients with lung cancer. Lung Cancer 2007; 56:415-21.

15. Brucker PS, Yost K, Cashy J, et al. General population and cancer patient norms for the Functional Assessment 
of Cancer Therapy-General (FACT-G). Eval Health Prof 2005;28:192-211.

16. Paull DE, Thomas ML, Meade GE, et al. Determinants of quality of life in patients following pulmonary resection for lung cancer. Am J Surg 2006;192:565-71.

17. Moller A, Sartipy U. Changes in quality of life after lung surgery in old and young patients: are they similar? World J Surg 2010;34:684-91.

18. Pompili C, Koller M, Velikova G, et al. EORTC QLQ-C30 summary score reliably detects changes in QoL three months after anatomic lung resection for Non-Small Cell Lung Cancer (NSCLC). Lung Cancer 2018;123:149-54.

19. Ferguson MK, Parma CM, Celauro AD, et al. Quality of life and mood in older patients after major lung resection. Ann Thorac Surg 2009;87:1007-12; discussion 12-3.

20. Yang P, Cheville AL, Wampfler JA, et al. Quality of life and symptom burden among long-term lung cancer survivors. J Thorac Oncol 2012;7:64-70.

Cite this article as: Liu Y, Yang W, Yang J, Liao S, Liu Z, Zeng B, Cheng C. Impact on quality of life after vagus nerve and phrenic nerve guided systematic nodal dissection for nonsmall cell lung cancer patients: a prospective, single-arm clinical trial. Ann Transl Med 2021;9(24):1753. doi: 10.21037/atm-215820
21. Kocher GJ, Mauss K, Carboni GL, et al. Effect of phrenic nerve palsy on early postoperative lung function after pneumonectomy: a prospective study. Ann Thorac Surg 2013;96:2015-20.

22. Undem BJ, Nassenstein C. Airway nerves and dyspnea associated with inflammatory airway disease. Respir Physiol Neurobiol 2009;167:36-44.

23. Liu Y, Tao T, Li W, et al. Regulating autonomic nervous system homeostasis improves pulmonary function in rabbits with acute lung injury. BMC Pulm Med 2017;17:98.

24. Lutz W, Sułkowski WJ. Vagus nerve participates in regulation of the airways: inflammatory response and hyperreactivity induced by occupational asthmogens. Int J Occup Med Environ Health 2004;17:417-31.

25. Schwartz RM, Yip R, Flores RM, et al. The impact of resection method and patient factors on quality of life among stage IA non-small cell lung cancer surgical patients. J Surg Oncol 2017;115:173-80. 


\section{Appendix 1 Functional Assessment of Cancer Therapy-Lung (FACT-L) questionnaire (simplified Chinese version)}

\section{FACT-L（第四版）生活质量评分量表}

\section{附录 IV}

下面罗列了大多数和您相同疾病的病人认为是重要的陈述。请选择最近 7 天来最能描述你的状 况的数字。

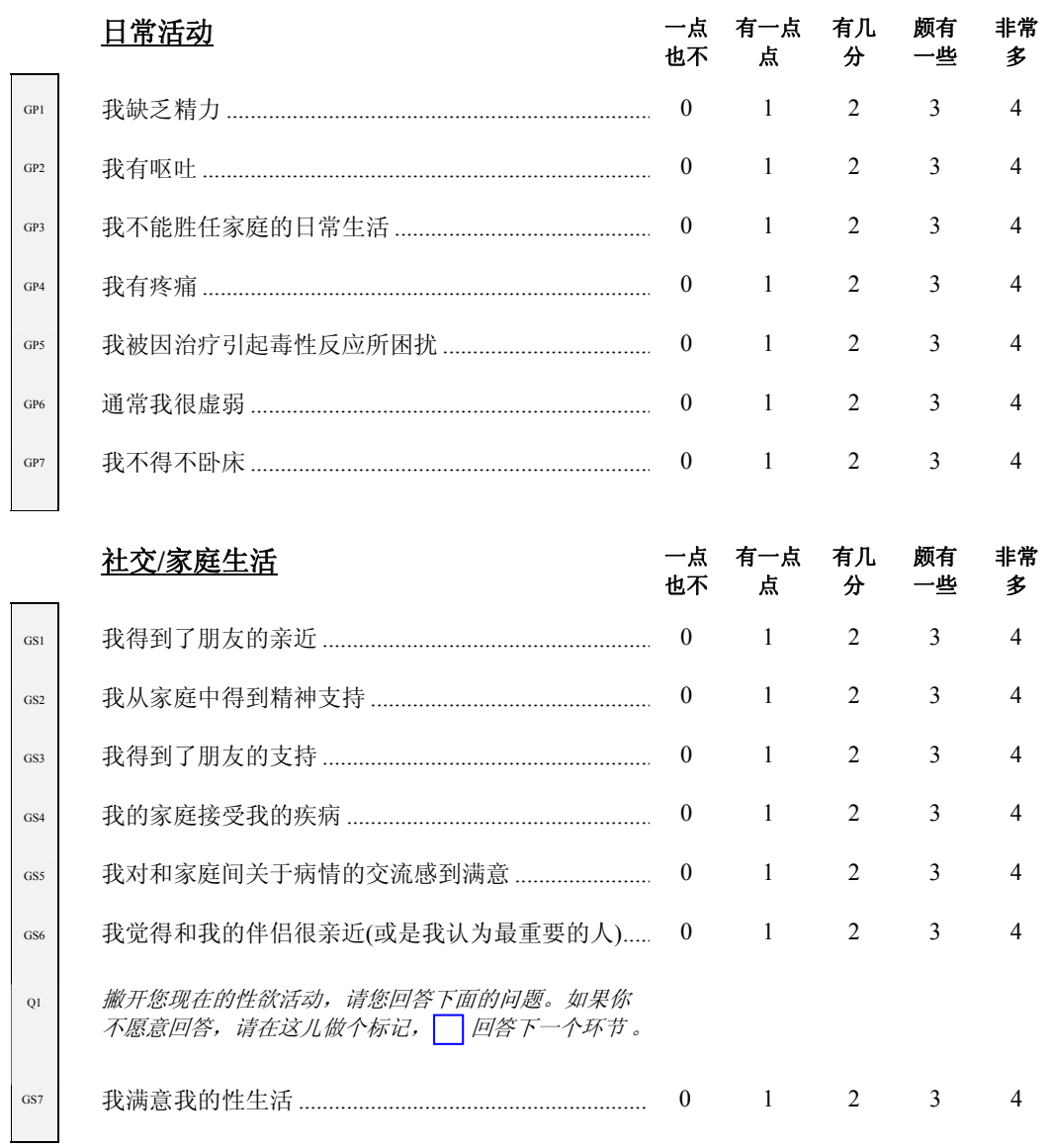


FACT-L（第四版）生活质量评分量表

请根据过去的 7 天您的情况, 在每一行陈述中圈明最符合您的数字。

情绪

我很悲伤..

我很自豪我能面对疾病

在与疾病斗争中,我感到失望

我感到很紧张

我害怕死亡

我担心我的情况会变的更坏

活动能力

\begin{tabular}{|c|}
\hline GF1 \\
GF2 \\
GF3 \\
GF4 \\
GF5 \\
GF6 \\
\hline
\end{tabular}
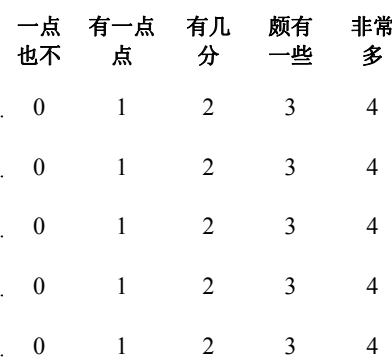

(1)

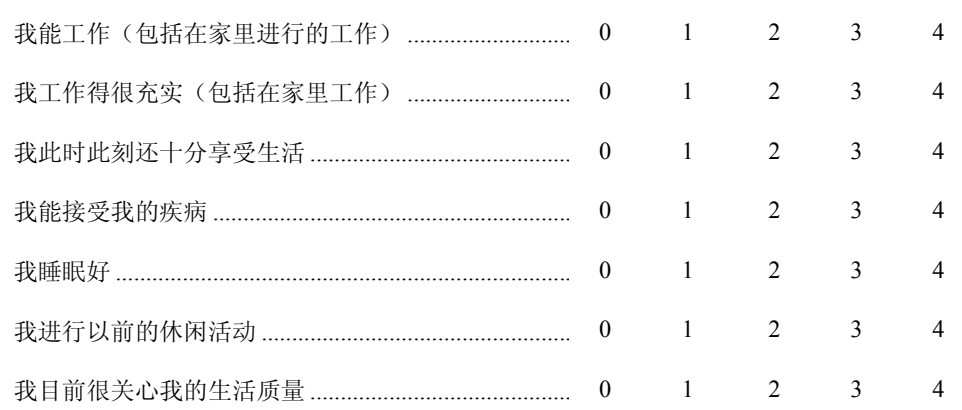


FACT-L（第四版）生活质量评分量表

请根据过去的 7 天您的情况, 在每一行陈述中圈明最符合您的数字。

\section{其他因素}

我感到气短

我的体重在下降

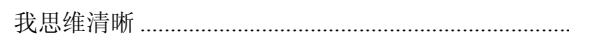

我有咳嗽

我为脱发而烦恼

我的食欲很好

我感到胸闷

我呼吸通畅

你曾吸烟吗

不__ 是_— 如果是请回答:

我对吸烟感觉后悔

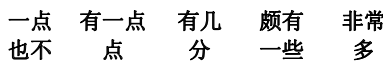

$\begin{array}{lllll}0 & 1 & 2 & 3 & 4\end{array}$

$\begin{array}{lllll}0 & 1 & 2 & 3 & 4\end{array}$

$\begin{array}{lllll}0 & 1 & 2 & 3 & 4\end{array}$

$\begin{array}{lllll}0 & 1 & 2 & 3 & 4\end{array}$

$\begin{array}{lllll}0 & 1 & 2 & 3 & 4\end{array}$

$\begin{array}{lllll}0 & 1 & 2 & 3 & 4\end{array}$

$\begin{array}{lllll}0 & 1 & 2 & 3 & 4\end{array}$

$\begin{array}{lllll}0 & 1 & 2 & 3 & 4\end{array}$ 